\title{
Construction 4.0 and its potential impact on people working in the construction industry
}

Article

Accepted Version

Sherratt, F., Dowsett, R. and Sherratt, S. (2020) Construction 4.0 and its potential impact on people working in the construction industry. Management, Procurement and Law, 173 (4). pp. 145-152. ISSN 1751-4304 doi:

https://doi.org/10.1680/jmapl.19.00053 Available at https://centaur.reading.ac.uk/90684/

It is advisable to refer to the publisher's version if you intend to cite from the work. See Guidance on citing.

To link to this article DOI: http://dx.doi.org/10.1680/jmapl.19.00053

Publisher: ICE Publishing

All outputs in CentAUR are protected by Intellectual Property Rights law, including copyright law. Copyright and IPR is retained by the creators or other copyright holders. Terms and conditions for use of this material are defined in the End User Agreement.

www.reading.ac.uk/centaur 
Central Archive at the University of Reading

Reading's research outputs online 


\section{Vive la révolution! But what about the people of Construction 4.0?}

\section{Author 1:}

Dr Fred Sherratt MCIOB CBuildE MCABE AMICE FHEA

Reader in Construction Management, School of Engineering and the Built Environment, Anglia Ruskin University, UK.

Orchid ID: ORCID Number 0000-0002-3255-7562.

\section{Author 2:}

Dr Ruth Dowsett

School of Construction Management and Engineering, University of Reading, Whiteknights, PO Box 217, Reading, Berkshire, RG6 6AH, UK.

\section{Author 3:}

Mr Simon Sherratt

PGR Student, Department of History, University of Essex, Wivenhoe Park, Colchester, Essex,CO4 3SQ, UK.

\section{Corresponding Author:}

Dr Fred Sherratt, School of Engineering and the Built Environment, Anglia Ruskin University, Bishop Hall Lane, Chelmsford, CM1 1SQ. 01245 683950, fred.sherratt@anglia.ac.uk

Word Count: 5402

$29^{\text {th }}$ April 2020 


\title{
Vive la révolution! But what about the people of Construction 4.0?
}

Fred Sherratt, Ruth Dowsett and Simon Sherratt

\begin{abstract}
Construction 4.0 is bringing change to our industry through digitization and technological innovation. Such change deliberately impacts 'traditional' ways of working, as it actively seeks to disrupt the norm and so enhance the effectiveness and efficiency of construction project delivery. Yet technology is not neutral, it brings with it an autonomy and an amorality that is potentially cause for concern. Here we draw on Ellul's theory of technique, as associated with technology, to unpack Construction 4.0 from critical perspectives and explore the potential it has to bring social and ethical challenges to our industry, and specifically its people. For example, trade workers may become usurped by technologies that automate their work, whilst professionals may find their roles within the design, engineering and construction processes become more heavily influenced and shaped by the technologies themselves. Indeed, the role of the 'technology owner' may become more powerful than any traditional profession in the future, as they become dominant actors within the construction industry space. This paper aims to stimulate discussion and debate in this area, and encourage the development of a more critical voice to supplement the technocratic optimism that currently surrounds Construction 4.0.
\end{abstract}

Keywords: Construction 4.0; ethics; Technique; Technology.

\section{Introduction}

We are currently experiencing the fourth industrial revolution (4IR). The integration of new information and communication technologies (ICTs) with manufacturing processes is changing industrial behaviours, impacting both products and procedures, as well as transforming project, organisational and wider industry structures. Industry 4.0, as it is also termed, has been catalysed by the increasing use of new technologies, such as robots and additive manufacturing, which are in turn supported by digital data, connectivity and cyber systems (McGregor 2017), and brings with it promises of reductions in material, labour and processing costs, and consequential improvements in productivity and efficiency (Dalenogare et al 2018).

Such promises not only find excellent fit with contemporary economic thinking, but also resonate strongly with the construction and civil engineering sectors, which have long been accused of low productivity, low predictability, and a lack of collaboration, improvement and innovation (e.g. Farmer 2016). Indeed, the UK construction industry has been the subject of decades of reformfocused rhetoric (Green 2011), and innovation in all forms has long been championed as necessary to resolve issues of inefficiency. Industry 4.0, manifested in the industry-specific Construction 4.0 (FIEC 2017) has therefore (and perhaps somewhat inevitably) been presented as the solution to our industry's ills, buoyed by the wave of technocratic optimism that surrounds 4IR as a whole.

However, technologies mobilised to support innovation are not neutral (Ellul 1954), and inevitably bring both intended and unintended consequences to practice. In this paper we mobilise Ellul's concept of Technique to bring an alternative perspective of technological development and innovation. We have drawn on Ellul's work here, in lieu of others, because it incorporates and 
enables critical evaluation of both the ethical and social consequences of technology in practice, and thus enables us to explore the Construction 4.0 phenomenon in these broad terms. This allows us to begin to frame alternative questions around it that have to date remained unasked, although we must confess that there are no easy solutions or answers to the issues highlighted. We must also acknowledge the UK-centric perspective presented here; construction is not a globally homogenous industry and thus Construction 4.0 will not be a homogenous revolution. Yet here we aim to start a conversation that we hope is able to finds fit on a bigger stage, and present a way of understanding applicable to other contexts and places. We aim to unpack some of the challenges that we feel face the UK industry as a result of this ongoing revolution, and explore the potential consequences for the people who work therein, be they trade workers, industry professionals or the new actors already emerging within our construction industry of the future.

\section{Constructing the Revolution: The Reform Agenda}

The construction industry has long been the subject of a reform agenda (for a more detailed consideration see Green 2011 or Smiley et al 2014 - both able to provide a more expansive consideration of this phenomenon). In the UK, reports upon reports - from Latham (Constructing the Team) in 1994, to Egan (Rethinking Construction) in 1998, to Wolstenhome (Never Waste a Good Crisis) in 2009, and most recently the Farmer (Modernise or Die) review of 2016 - have established an almost constant discourse of change, improvement and reform. Values of reduced time, lower costs and increased speed dominate (Smiley et al 2014), painting a picture of an industry that in its current incarnation is simply not good enough. Indeed, the UK Government's Construction 2025 Strategy (HM Government 2013) was firmly aligned to this discourse of change and reform, making demands that UK construction become 'Smart' and 'technologically advanced' (ibid 2013: 6), as well as improve on project delivery and costs by 50\% and 33\% respectively by 2025 (ibid 2013:7).

Such debates about improvement and industry reform are therefore nothing new, and the discourse of reform does not stop with critique of current work practices and sub-benchmark outputs. Another complementary discourse has also long permeated the industry; that of innovation (Orstavik et al 2015; Dainty et al 2017). Innovation is positioned as both necessary and vital in solving the industry's problems. As Farmer (2016:13) stated in his scathing critique of contemporary UK construction industry operations: 'Other industries have harnessed wholesale process improvement by embracing and commercialising the role of technology and have effectively reinvented themselves by driving a paradigm shift in their end-to-end delivery.' For Farmer, innovation through technology is the straightforward solution to the UK construction industry's ills, and all that is needed is the implementation of technologies for success.

Yet innovation in construction is arguably much more complex than this, and industry context is all important. Harty (2005) suggested five features of the construction industry that have significant bearing on the adoption of innovations in practice: the need for collaboration, its project-based nature, the modes of communication and information transfer, inter-organisational operations, and the way power is distributed in practice. Innovation in construction is challenging, its structure and ways of working relatively unique, and to draw on the success of innovation in other industries as evidence of guaranteed triumph in construction is not only problematic, but can actually further 'complicate the adoption of new tools and processes' in practice (ibid 2005:513).

Yet the speed of change under 4IR is accelerating. Technological innovations are becoming more frequent and new developments are publicised on a regular basis. Change is occurring at a pace described as 'exponential' by Brynjolfsson and McAfee (2014), and although the construction industry has lagged behind, it has recently been suggested that Construction 4.0 is now more 
persistently 'seeping into the ... industry' (World Economic Forum 2018:8). It would appear that the solutions to many long-term industry 'problems' are now finally arriving, and when set against a backdrop of ongoing improvement agendas and the inevitable desire for increased profit within our contemporary neoliberal economy, solutions with the capacity to add value whilst reducing costs could not be more welcome. Indeed, change is not only desired, but also now inevitable.

\section{Vive La Révolution! Construction 4.0 in Practice}

For the construction industry, 4IR arguably took its first steps with Building Information Modelling (BIM). BIM was heralded as the catalyst to 'revolutionise construction practice, through intelligence, efficiency and integrated project delivery...' (Dainty et al 2017:697) and the UK government agreed, mandating that all their projects '....will require fully collaborative 3D BIM (with all project and asset information, documentation and data being electronic) as a minimum by 2016' (HM Government 2011:14). However, this target was not achieved and current BIM activity within the industry has still to reach the levels of application originally envisaged. Building's 2018 survey of UK BIM-in-Use (Champ 2018) showed that although $73 \%$ are using BIM in some form, only $48 \%$ are achieving BIM Level 2 (rather than 3D as per the government's target) and this is mainly for clash detection and collaborative design, as well as impressing clients with 3D models and 'fly-throughs' of their future projects. The promise has certainly not been realised in practice, and BIM has arguably become a sophisticated document control system rather than the catalyst for the Construction 4.0 revolution.

More recently a wide variety of innovations and technologies have emerged, surrounded by the same technocratic optimism and discourse of revolutionary progress that first accompanied BIM, heralding Construction 4.0 as the panacea for positive industry change. Specific examples include robots that can now lay bricks within factory environments (Quirke 2018) and they may soon be seen out on site, as the technology able to support basic low-level robotic motor skills that would enable them to cross uneven ground is being developed at an extraordinary rate (Brynjolfsson and McAfee 2014). Robotic-human exoskeletons have also been created, able to give workers 'superhuman' powers, alleviating the problems associated with manual handling and other repetitive physical operations, whilst also increasing productivity (Gammon 2017). Autonomous geotechnical plant and machinery controlled by Artificial Intelligence (Al) rather than human drivers (Construction Manager 2018) that uses satellite technologies for guidance can already be found on UK sites, undertaking groundworks with scientific precision and no need for chain lads or anything as rustic as travellers. Drones are able to survey, set-out and even perform light lifting operations (Gammon 2017), whilst additive manufacturing (3D printing) is changing the production of construction materials and components, and even entire construction projects themselves, as seen in the 'construction' of 3D-printed houses within the factory setting (New China TV 2016).

Design processes have also seen change. The use of BIM, its 3D modelling capabilities and data sharing has been further supplemented by the use of other technologies, such as glasses that use Augmented or Virtual Reality (Piroozfar et al 2018) within the process of design. The use of Artificial Intelligence (AI), Machine Learning, the Internet of Things (IOT) and Digital Twins has further enhanced the potential for BIM models to be used for construction planning and co-ordination (4D $\mathrm{BIM}$ ) and financial management (5D BIM), with real-time data processing and adaptive machinelearning able to optimise construction activities (FIEC 2017) and therefore take on the role of 'construction management' itself.

However, such developments and technological innovations are still relatively piecemeal, addressing or providing a technological solution to specific problematic aspects of industry practice, and they are arguably seen much more in press-releases, industry magazines and social media than they are 
on any construction site. It will be through effective 'recombinant innovation' (Brynjolfsson and McAfee 2014), where the most appropriate technologies for design, manufacture, assembly, construction and operation are combined, that will result in a holistically new approach to construction practice. A fundamental restructuring of how we build and construct, grounded in BIM as first envisaged and Digital Twin modelling, has the potential to create a future where construction work will occur with very different types of human involvement, something already found in industry rhetoric and discourse, and beginning to be realised in practice.

\section{Technology and Technique: Understanding Construction 4.0}

Given the current trajectory of Construction 4.0, it is timely that we should perhaps pause and carefully consider the potential ethical and social challenges it may also bring before we wholeheartedly embrace it as the saviour of the built environment. We should certainly reflect upon the ways in which it has been adopted and mobilised by our industry, and the possibility for both intended and unintended consequences to emerge from its implementation. Here we draw on the work of Jacques Ellul (1954) to explore this phenomenon in more detail, to reframe our understandings of technology through a lens able to readily highlight the ethical and social challenges therein.

In his work The Technological Society (1954), Ellul questioned the nature of the links between technology, society and the place of people in this milieu. He suggested that there are fundamental aspects of the 'technological process', a process that has seen our lives become ever more reliant on technology and technical developments, that are rarely addressed and little understood.

Technology, states Ellul, needs to be understood as something far more than simply a means by which (through innovation, invention and improved organisation) the needs of society are met more effectively. Instead technology should be viewed as part of a wider (all-encompassing) process of technique, defined as 'The totality of methods rationally arrived at and having absolute efficiency (for a given stage of development) in every field of human activity' (Ellul 1954:xxv). Essentially, the lens of technique starkly reveals that technology is not, in and of itself, neutral.

It is technique that forms and frames our world; it is our environment. It is the space in which industry, economics, politics and people are now situated, and our activities are now defined by technique, which includes technologies such as mass and social media. For example, within the construction industry the consequences of technique can be readily identified in changes to Corporate Social Responsibility (CSR) practices. It is technique that shapes and directs CSR towards activities best able to provide appropriate content for corporate or project websites, tweets and other social media technologies that now constitute organisational brands and profiles (Sherratt 2017a; 2017b). Essentially, the technological medium now dictates the message (McLuhan and Fiore 1967), and technique dictates both organisational activities and our expectations of them: this is how we now do CSR in construction. This clearly raises ethical questions around the 'new CSR': for example, are industry efforts for worker health really best directed to the photogenic activity of providing breakfast fruit to site workers, rather than far less glamourous but much more ethically sound endeavours to protect workers against site dust and long term occupational diseases? (Sherratt 2017b).

As Ellul noted, a typical response to the ever increasing use of technology is that it is 'meeting the needs of society' by, for example, allowing it to communicate better or live longer. From construction industry perspectives, this 'need' is also clearly articulated through a perpetual industry reform rhetoric, yet the lens of technique brings into focus a number of ethical and social challenges within the seeming simple technological solution offered by Construction 4.0. 
Fundamental to this consideration is the autonomous nature of the process of technique itself. Given the rational and objective methods that are its driving force, technique lies beyond ethical judgement or questioning. As Ellul (1954:97) states: 'A principal characteristic of [technology]... is its refusal to tolerate moral judgements. It is absolutely independent of them and eliminates them from its domain... creat[ing] a completely independent technical morality.' It therefore takes on a paradoxical nature, as rather than meeting the needs of society, it instead compels society to perpetually adapt (whether it wants to or not) in order to meet the dictates that technique imposes upon it. A consequence of these rational foundations is that debates regarding the moral and ethical 'rights and wrongs' of technological developments are simply deemed irrelevant within the inevitable march of progress. Yet such progress can bring significant ethical and social challenges. The very first industrial revolution in Britain (1IR, as it were) changed life for many beyond all recognition as 'writers... beg[a]n to catalogue the social and human costs resulting from the systematic application of science and technology to the production of life's necessities and wants. Populations were dislocated, communities and neighbourhoods destroyed, local cultures undermined in order to prepare conditions congenial to modern industry.' (Wolin 2004 [2016]:400). Whether this was a revolution for better or worse can now be argued from a variety of different ethical and social positions of course, depending on perspectives of quality of life, tradition and history, and perhaps most relevant today, climate change.

This amorality and autonomy of technique is supplemented by its inevitability. There is seemingly no choice: technological developments are coming, and so industries and their workforces must change in order to meet new technical demands. For example, a report from the US White House (Executive Office of the President 2016:2) states that: 'Public policy can ... ensur[e] that workers are retrained and able to succeed in occupations that are complementary to, rather than competing with, automation.' But change, in the form of automation, is itself inevitable. The process of technique means that society becomes fully submissive to its implementation, people are a resource that needs to be 'retrained' so as to adapt to technology, rather than the other way around. Indeed, as Mander (1996:344) notes, 'Society accepts the onrush of... technologies with alarming passivity, and without any systematic consideration of the social and political changes they bring.' This is able to explain how technocratic optimism can be so easily sustained, even in the face of something as fundamentally negative as the removal of jobs from large numbers of skilled workers. Indeed, Ellul himself sought to proffer a potential solution to such destructive consequences, proposing an 'ethics of non-power' in which a society finds itself '...capable of doing something and deciding against it' (Ellul 1980:245). However, whilst such a notion finds harmony with Ellul's (and likely many others') personal moral and ethical ethos, it struggles to find fit with the realities of our neoliberal and globalised market place. Unfortunately, history suggests that Ellul's thesis holds true, it is technique that holds the power, and we are now witnessing the march of 4IR irrespective of its impact on the current workforce.

We must therefore acknowledge that Construction 4.0 is operating within the wider auspices of technique. It is not neutral and instead has an autonomy, amorality and inevitability that is reshaping our expectations and understandings of what the construction industry is and how it should work, and who holds the power therein. Despite concerns about the ethical and social consequences, it is technique that enables their easy dismissal, as arguments against it cannot be framed without those asking them being seen as 'Luddites'. Indeed, as Construction 4.0 is comprised of rational and efficient processes that find excellent fit with our contemporary industrial problems, why is such challenge even necessary when there is clearly no other option? 


\section{Will Robots Steal our Jobs? The People of Construction 4.0}

But challenge we should. Construction 4.0 is bringing a revolution to our industry, but more specifically, as Ellul councils, technique will reshape our industry to suit the incoming technologies rather than adopt and adapt technologies to enhance our industry as is. Ours is an industry which contributes significantly to employment, in the UK approximately $9 \%$ of the workforce is employed in the construction industry (ONS 2019), and particularly the employment of those who have struggled with formal traditional education. The social consequences of radical change for this workforce could therefore be considerable, making the lack of contemporary debate in our industry of any associated ethical and social challenges a significant concern.

\section{Who are 'the Workers'?}

Those who undertake manual construction work, be they trade-skilled or not, have long been unacknowledged in our industry. The names of the navvies who laboured and died to build the railways of the UK are not those carved into the walls of the Institution of Civil Engineer's prestigious London headquarters, it is those of the chief engineers who are writ large. Traditional trades and the '...skills of building workers are devalued' (Ness 2009:652), such jobs described as 'dirty and dangerous' by the World Economic Forum (2018:20), with 'manual methods' blamed for the industry's poor levels of production (ibid 2018:7).

Worryingly, manual workers are also noticeably missing from the discourse of Construction 4.0, which presents the industry as a professional, management, white-collar space (Ness 2009), adding 'high-tech' aspects and enhanced engineering, creative and design skills (Brynjolfsson and McAfee 2014:135). Skills such as Al, data analysis and programming, robotics, modular design and engineering, as well as lean process skills and logistics specialists (World Economic Forum 2018) have all been added to the list of requirement for the construction workers of the future. Despite promoting such Construction 4.0 skills as being necessary 'transformation imperatives', the World Economic Forum (2018:19) illustrated the need to 'attract new talent and build required skills' with an icon of a person - but that person is wearing a tie and not a hard hat (and never mind issues of gender). The future workers of Construction 4.0 are seen as able to innovate and have 'bigger ideas' (Scoones 2018), and to challenge and reform construction in ways we cannot yet even imagine - but they do not lay bricks, stand in the cold, get muddy, or as Ness put it 'scratch [their] nail varnish' (2009:649).

Construction 4.0 has seen a blurring of the trade and professional workers that make up the industry, the former vanishing as technology, or specifically technique, changes expectations of how and specifically who does construction. Technique engenders the inevitability of Construction 4.0 to demand an entirely different workforce, to autonomously dictate the skills required therein, and to therefore negate and ultimate eliminate the value and contribution of those who actually build things in real life. Indeed, the new high-tech skills required can clearly be linked to the 'digital divide', as the skills to use ICTs and technologies are not distributed equally within society. Disparities often align to socioeconomic status and education (Epstein et al 2011) in eerily similar ways to the existing alignment of professional and trade skills found within the construction industry.

\section{Site Work and Trade Workers}

For now, we still need people working out on our sites, but progress under Construction 4.0 may change this, as a reduction in the total number of workers is seen as inevitable with increased use of technology (Brynjolfsson and McAfee 2014). It has even been suggested that almost $50 \%$ of 
traditional construction work could be automated over the next 20 years, as a consequence of fundamental re-designs of construction processes and practices (Frey and Osborne 2017). Concerns should not therefore focus on a like-for-like replacement of workers with robots, but more a consideration of the consequences of recombinant innovations (a point we have not yet reached under Construction 4.0), involving both technologically enhanced processes and mechanisation, that result in the most significant impacts. For example, the introduction of computer technology and new printing machinery to the newspaper production industry in London in the late 1970s rapidly saw the decimation of the skilled compositor trade (Cockburn 1983), fundamentally changing the way the industry was structured and operated. In this instance robots didn't replace workers, the technology made them totally defunct. Similarly, within the construction industry, trade workers should perhaps not be worried that they will be replaced by robots, but rather be more concerned that the way construction production processes occur in the future will not require their input at all (Brynjolfsson and McAfee 2014:138).

The Construction 4.0 discourse does come with its own narrative of re-skilling (FIEC 2017) or multiskilled workers with 'new competencies and skills' (Dalenogare et al 2018:385), but for many this may result in a downgrading of their role and earning potential. Echoing the workforce skills changes as seen in the industrial revolutions of the past, this is unlikely to result in a homogenous deskilling of the workforce, but rather a simultaneous deskilling of a large part of the workforce whilst raising the demand for some, far fewer, highly-skilled workers (Brugger and Gehrke 2018). For example, in their study of the development of reinforced concrete in France, the UK and the US, Schweber and Harty (2010) found that traditionally skilled workers were replaced by two other roles: degree-qualified engineers to supervise the materials, and unskilled workers to mix and pour. The role of any skilled craft or tradesman in this process was eliminated. Indeed, the biggest threat to workers from Construction 4.0 may come from negative changes in the quality of their work, rather than the loss of work itself (Spencer 2018). Although either option is not all that palatable, the amoral nature of technique creates a convenient myopia for the social consequences such changes could bring for construction, in terms of the numbers of people employed, their potential earnings, and the self-actualisation and self-worth they are able to realise from their work.

\section{Construction Professionals}

The introduction of technology has already changed the role of many construction industry professionals. For example, the use of 3D technology for structural engineering design resulted in engineers, who had previously undertaken practical engineering work, seeing their role change to one of a metaphorical, 'air traffic controller', whose dominant task was to sit in front of their computer supplying information and guiding subcontractors (Gal et al 2008). This deprofessionalization of work to the point of performative instruction could have ethical and social consequences yet to be understood.

New roles are also created to enable and facilitate the use of new Construction 4.0 technologies that, intentionally or unintentionally, weaken the professional autonomy of practitioners. For example, the introduction of BIM initially saw power struggles within traditional design teams, and a necessary deference to the new role of the 'BIM co-ordinator'. Bosch-Sijtsema (2013), for example, describes a case from Sweden in which the ICT coordinator of a BIM-enabled design commandeered control of the project's clash detection meetings, using their technical authority and skills to navigate the 3D model and interpret the clash detection reports it produced. Similarly, Akintola et al (2017) found that in South Africa new standalone BIM roles rapidly gained power in the absence of BIM skills within the traditional design team membership, using their understanding of the technology as a strategic resource to do so. Such power was transient whilst practitioners gained 
the relevant technical skills and knowledge to reclaim their work jurisdiction and over time develop new work practices and relationships alongside the technology. However, the tensions that occur in the development of professional roles between existing and prospective roles centre on the tasks the technology performs. BIM professional roles are 'institutional agents' that define and translate technique applying pressure on non-BIM professionals to adapt (Bosch-Sijtsema and Gluch 2019). So whilst the traditional design practitioners in Akintola et al's (2017) study may have reclaimed their position and legitimacy by re-skilling and gaining new knowledge, this expertise is itself was defined by the functionality of the technology, through technique.

The perceived inherent value within Construction 4.0 technologies shifts power within traditional project teams, determining and defining new professional roles and structures. Schweber and Harty (2010), drawing upon Abbott (1998), stated that 'technological innovation is always (also) a bid to (re)define the work process, while the negotiations surrounding the uptake and use of new objects are inevitably also struggles for the definition and control of a new work jurisdiction.' Change to work practices identified in other countries is therefore also likely to emerge in the UK, where design teams have seen most change thus far. However given the potential for Construction 4.0 to also redefine the planning, programming, resourcing, costing and management of our projects and, given the inevitability of technique, such change is likely to reach all those in traditional professional and management roles in due course (see Leicht and Sherratt 2019 for an existential consideration of the role of the Construction Manager in the US).

\section{The New Actors of Construction 4.0}

A new role, the 'technology owner', may even become more powerful than any traditional profession in the future, as they become dominant actors within our industry through the power conferred on them by technique. BIM, in the UK context at least, was never focused on the adoption of technology. It was an industry-led initiative designed to improve the management and coordination of project information, actually looking to adopt sound principles and fairly basic technology rather than 'cutting edge IT'. However BIM soon became a catch-all term for 3D modelling software, which was far more attractive and so overshadowed and neglected the improved information management process it was originally meant to be. Software developers and vendors offered enterprise agreements, promising solutions to all manner of construction process inefficiencies, and thus redesigning industry structures to fit their technologies. Autodesk, for example, now comprises around sixty-nine acquisitions, the latest being a platform to improve bidmanagement processes within construction. As CEO Andrew Anagnost (2018) told Forbes: We are trying to completely digitize the construction process all the way from design to build ... we feel we have acquired all the important assets we need.' This is an attractive place to trade, the global construction software market is expected to reach \$10billion by 2020 (Marr 2019), and Autodesk, and many others, intend to maximise their opportunities, Ellul's 'ethics of non-power' rendered impotent in the face of such potential.

This focus on technological functionality and a confidence, bordering on arrogance, that technology developers can capture (and inevitably improve) construction industry practices and processes is clearly illustrated by the term 'computer controlled craftsmanship.' Technology providers have become gurus to the industry, with little sense of history, craft or profession. They are gaining legal ownership of the design (in the form of digital twin models) and processes (through robotics, $\mathrm{Al}$ and assembly systems) that make up construction projects, and with such ownership also comes power. This power will enable technology companies, supported actively by economics and politics and more subtly and passively by technique, to dictate the future design, manufacturing and assembly processes that make up the construction industry. The consequences of this could be considerable, 
resulting in a built environment shaped and constructed to meet the dictates of technology, rather than the manifestation of the imagination, fun, creativity and humanity of an architect.

\section{Concluding Thoughts}

Construction 4.0 has been a most serendipitous revolution for a struggling construction industry, able to bring about the positive changes desired by the ubiquitous reform agenda, always desperate for innovation and change. Corporations and technology owners have been granted the power to lead the industry metamorphosis towards Construction 4.0, to develop efficiencies and savings that bring with them increases in productivity, and so also respond to governmental desires for improvement, continued growth and market activity. Yet to focus only on the potential gains to be made in productivity, efficiency and profits, we are in danger of overlooking the bigger industry picture by neglecting consideration of any ethical and social consequences that may also result from the Construction 4.0 revolution and the impact it may have on its people.

We can learn much from Ellul's theory of technique. We should be aware of how technology is not only bringing but also shaping our expectations of change, and doing so with autonomy, amorality and an inherent inevitability. For a discipline where industry engagement is key, it is all too easy to fall into the trap of simply accepting the dominant discourses of 'progress' and 'growth' as societal norms, and simply aligning our actions to suit. We need to more explicitly consider why and how our industry is adopting and adapting to technological change, and perhaps explore the potential behind Ellul's ethics of non-power, or more simply just ask 'just because we can, does that mean we should?' We should be minded that the organisations leading our Construction 4.0 revolution are inevitably focused on profit and growth, rather than motivated by ethical and socially beneficial motives, and so as Noam Chomsky argued (1967:12) we perhaps should "trouble [our]selves over moral issues and human rights, or over the traditional problems of man and society". It should be our role, as academics and industry professionals, to be thoughtful, critical, and to look beyond such unspoken assumptions and ensure they are challenged where appropriate, or at the very least acknowledged. Here, Ellul's lens of technique has enabled us to begin to do just that, albeit on a very limited scale and there is of course scope to do much more.

Our industry does much more for the world that simply create the spaces in which people live, work and play - it also employs vast numbers of workers worldwide, providing their income and support from activities that in return provide pleasure in their tangibility, collegiality and creativity, as well as the use of craft skills and ability. The contribution the construction industry makes to social wellbring and social value is therefore considerable, but this is something the Construction 4.0 agenda seems to be currently overlooking. We should perhaps be asking, for example, whether Construction 4.0 will create a world people want to live and work in? Who directs and shapes its development, and whose needs does it serve? Who benefits from this process and who loses out, and what role does (or more importantly should) humanity play in this revolution?

It could be argued that the Construction 4.0 revolution is precisely what is required, that the dinosaur that is the global construction industry requires such a seismic shift for progress. But we should not perhaps be quite so dazzled and distracted by technology and technique and should more carefully consider what progress could and should looks like. We should consider ethical and social consequences within a much more critical agenda in this area, able to theoretically and empirically challenge the dominant discourses of technocratic optimism and determinism that currently surround it. Future work should more clearly acknowledge the influence of technique within the change process, the wider political and economic contexts in which this revolution is occurring, and the potential power imbalances inherent in Construction 4.0. Here we have asked 
many questions, but have not sought to provide the answers. Yet we should, as an industry community of practitioners and academics, be able to provide more measured and balanced evaluations and indeed responses to the notion that Construction 4.0 will change our industry only for the better, and instead seek to ensure the recognition and championing of those who actually construct and build the world we live in now, and in the future.

\section{References}

Akintola, A., Venkatachalam, S. and Root, D. (2017) New BIM Roles' Legitimacy and Changing Power Dynamics on BIM-Enabled Projects, J. Con Eng Man, 143(9).

Anagnost, A. (2018) Quoted in Forbes "Why Autodesk just spent $\$ 1.15$ billion on two construction tech startups". Online, available:

https://www.forbes.com/sites/alexkonrad/2018/12/20/why-autodesk-just-spent-115billion-on-two-construction-tech-startups/\#35275ff432ab (30th July 2019)

Bosch-Sijtsema, P. (2013) "New ICT changes working routines in construction design projects". Nordic Academy of Management (NFF) Iceland, August 2013

Bosch-Sijtsema, P. and Gluch, A. (2019) "Professional development of the BIM actor role" J. Aut in Con. 97(1), 44-51

Brugger, F. \& Gehrke, C. (2018). "Skilling and deskilling: technological change in classical economic theory and its empirical evidence". Theory and Society. 47:663-689.

Brynjolfsson, E. and McAfee, A., (2014). The Second Machine Age: work, progress and prosperity in a time of brilliant technologies, Norton, NYC, USA.

Champ, H., (2018). "BIM Survey 2018: The Rise and Rise of BIM," Building Magazine, 24th October 2018.

Chomsky, N., (1967). "The Responsibility of Intellectuals," A Special Supplement, The New York Review of Books, February 23.

Cockburn, C. (1983) Brothers: Male Dominance and Technological Change, Pluto Press, London.

Construction Manager (2018) "Skanska and Volvo develop autonomous quarry," Construction Manager Magazine, the Chartered Institute of Building, 15 October 2018.

Dainty, A., Leiringer, R., Fernie, S. and Harty, C., (2017). "BIM and the small construction firm: a critical perspective," Building Research and Information, 45(6), 696-709.

Dalenogare, L.S., Benitez, G.B., Ayala, N.F. and Frank, A.G. (2018). "The expected contribution of Industry 4.0 technologies for industrial performance" Int. J. Prod Econ. 204, 383-394.

Egan, J., (1998). Rethinking Construction, Report of the Construction Task Force, Department of the Environment, Transport and Regions, Crown Copyright, UK.

Ellul, J., (1954). The Technological Society, Vintage, Toronto.

Ellul, J. (1980) 'The power of technique and the ethics of non-power', in K. Woodward (ed.), The Myths of Information: Technology and Postindustrial Culture, Coda Press, Madison, USA, 242-247.

Epstein, D., Nisbet, E.C. and Gillespie, T., (2011). "Who's Responsible for the Digital Divide? Public Perceptions and Policy Implications," The Information Society, 27, 92-104.

Executive Office of the President (2016) Preparing for the Future of Artificial Intelligence. National Science and Technology Council Committee on Technology, Washington DC. 
Farmer, M., (2016). The Farmer Review of the UK Construction Labour Model: Modernise or Die, Construction Leadership Council, UK.

FIEC, (2017). Safeguarding in the next industrial revolution, European Construction Industry Federation, Construction Europe, November, pp. 19.

Frey, C.B. and Osborne, M. A. (2017). 'The future of employment: How susceptible are jobs to computerization?" J. Tech Forc and Soc Chan. 114, 254-280.

Gal, U., Lyytinen, K. \& Yoo, Y. (2008). "The Dynamics of IT Boundary Objects, Information Infrastructure, and Organizational Identities: The introduction of 3D modeling technologies into the architecture engineering and Construction Industry", Eu. J. of Info. Sys. 14, 290-304.

Gammon, (2017). "The rise of robotics: Gammon technologies and the changing face of construction," The Record, Gammon, online, available:

https://www.gammonconstruction.com/uploads/files/press/the record/The\%20Record 20 17\%20issue\%201.pdf [25 November 2018]

Green, S., (2011). Making Sense of Construction Improvement, Wiley-Blackwell, Chichester, UK.

Harty, C., (2005). "Innovation in construction: a sociology of technology approach," Building Research and Innovation, 33(6), 512-522.

HM Government, (2011). Government Construction Strategy, Cabinet Office, London, UK.

HM Government, (2013). Construction 2025 Industrial Strategy: government and industry in partnership, Crown Copyright, UK.

Latham, M., (1994). Constructing the Team, HMSO, UK.

Leicht, R. and Sherratt, F. (2019) The Existential Crisis of Construction Project Managers: who, what and why are we anymore? Engineering Project Organisation Conference, Vail, USA, 25-27 June 2019, Engineering Project Organisation Society.

Mander, J. (1996). "Technologies of Globalisation." The Case Against the Global Economy and for a Turn Toward the Local, J. Mander and E. Goldsmith, eds., Sierra Club Books, San Fransisco, 344-359.

Marr, B. (2019) "How big data and analytics is transforming the construction industry" Online, available: https://www.forbes.com/sites/bernardmarr/2016/04/19/how-big-data-andanalytics-are-transforming-the-construction-industry/\#75e95c5e33fc (30th July 2019)

McGregor, L., (2017). "Industry 4.0 - What does the fourth industrial revolution (4IR) mean for UK business?" Innovate UK, UK Government, online, available: https://innovateuk.blog.gov.uk/tag/industry-4-0/ [25 November 2018]

McLuhan, M. and Fiore, Q., (1967). The Medium is the Massage. London: Penguin Books.

Ness, K., (2009). "Not just about bricks: the invisible building worker." In Dainty, A. (Ed) Proceedings of the 25th Annual ARCOM Conference, 7-9 September 2009, Nottingham, UK, Association of Researchers in Construction Management, 645-54.

New China TV (2016) 3D printers print Chinese courtyard in a week, available: https://www.youtube.com/watch?v=4rvKP yfcGM [15 December 2019].

Office for National Statistics (2019) Employment by Industry, UK Government, online, available: https://www.ons.gov.uk/employmentandlabourmarket/peopleinwork/employmentandempl oyeetypes/datasets/employmentbyindustryemp13 [5 June 2019]

Orstavik, F., Dainty, A.R.J. and Abbott, C., (2015). Construction Innovation, Wiley Blackwell, Chichester, UK. 
Piroozfar, P., Essa, A., Boseley, S., Farr, E.R.P. and Jin, R., (2018). "Augmented Reality (AR) and Virtual Reality (VR) in the construction industry: An experiential development workflow," Proceedings of the Tenth International Conference on Construction in the 21st Century (CITC10), July 2nd-4th, Colombo, Sri Lanka.

Quirke, J., (2018). "Hadrian the bricklaying robot builds complete house in three days," Global Construction Review, 15 November 2018.

Schweber, L. and Harty C.F. (2010). "Actors and objects: a socio-technical networks approach to technology uptake in the construction sector", Construction Management and Economics, 28:6, 657-674.

Scoones, E., (2018). "A biologist, a roboticist and a coder walk onto a construction site...," Building Magazine, 19th October 2018.

Sherratt, F., (2017a). "Shaping the Discourse of Worker Health in the UK Construction Industry," Construction Management and Economics, 36(3), 141-152.

Sherratt, F., (2017b). "The Commodification of Worker Health, Safety and Well-being: CSR in Practice," In: Emuze, F. and Smallwood, J. (Eds) Valuing People in Construction, Spon Research, Routledge, London, pp 209-225.

Sherratt, F., (2017c). "Mirror, Mirror on the Wall - What are Academics Really doing for People in Construction?" (Keynote) In: Emuze, F. and Behm, M. (Eds) Proceedings of the Joint CIB W099 and TG59 International Safety, Health, and People in Construction Conference, 11-13 June 2017, Cape Town, South Africa, CIB, ISBN: 978-1-920508-78-4, pp. xi-xiv.

Smiley, J-P., Fernie, S. and Dainty A., (2014). "Understanding construction reform discourses," Construction Management and Economics, 32(7-8), 804-815.

Spencer, D. (2018). "Fear and hope in an age of mass automation: debating the future of work". New Technology, Work and Employment 33:1, https://doi.org/10.1111/ntwe.12105.

Wolin, S.S., (2004[2016]). Politics and Vision: Continuity and Innovation in Western Political Thought, Princeton University Press, USA.

Wolstenhome, A., (2009). Never Waste a Good Crisis, Constructing Excellence in the Built Environment, London.

World Economic Forum, (2016). Shaping the Future of Construction: A Breakthrough in Mindset and Technology, World Economic Forum, Geneva, Switzerland.

World Economic Forum, (2018). Shaping the Future of Construction: Future Scenarios and Implications for the Industry, World Economic Forum, Geneva, Switzerland. 